\title{
Application and Effect of Loading Rates on Coal Sample Failure
}

\author{
Genwei Li, ${ }^{1,2}$ Shuaifeng Lu, ${ }^{3}$ Sifei Liu $\mathbb{C}^{3},{ }^{3}$ Jing Liu, $^{2}$ Peng Shi, ${ }^{3}$ and Bowen Fan ${ }^{3}$ \\ ${ }^{1}$ College of Energy Engineering, Xi'an University of Science and Technology, Xi'an, Shaanxi 710054, China \\ ${ }^{2}$ Department of Mining Engineering, Lvliang University, Lvliang, Shanxi 033001, China \\ ${ }^{3}$ School of Mines, Key Laboratory of Deep Coal Resource Mining, Ministry of Education of China, \\ China University of Mining and Technology, Xuzhou, Jiangsu 221116, China \\ Correspondence should be addressed to Sifei Liu; cumtlsf@cumt.edu.cn
}

Received 23 December 2020; Revised 1 February 2021; Accepted 2 March 2021; Published 17 March 2021

Academic Editor: Junfei Zhang

Copyright (c) 2021 Genwei Li et al. This is an open access article distributed under the Creative Commons Attribution License, which permits unrestricted use, distribution, and reproduction in any medium, provided the original work is properly cited.

In order to evaluate the coal pillar stability in recovery of residual room pillars under different mining rates, this paper studies the influence of loading rate on the mechanical properties of the coal body. The uniaxial compression tests of coal samples in Yangcheng area at different loading rates were carried out with the MTS815 electrohydraulic servo rock mechanics test system. The stress-strain curves and the evolution characteristics of AE signals were analyzed. At same time, the mechanism of damage and failure of specimens are also discussed. The results show the following. (1) With the increase in loading rate, the ultimate stress and ultimate strain of specimens decrease first and then increase. (2) Loading rate has a significant effect on the stability adjustment of specimens. With the decrease in loading rate, the earlier the stress adjustment is, the larger the adjustment range is, and the failure mode changes from shear failure to tensile failure. (3) In addition, when the loading rate increases, the AE evolves from continuous dense to discrete catastrophe, which indicates that the failure of the sample at a larger loading rate is sudden, which is not conducive to the maintenance of the stability of the coal pillar. (4) Finally, the failure mechanism of the specimen structure under different loading rates is obtained, and the improvement measures for the effect of mining velocity of working face on the stability of coal pillar are put forward. The results reveal the loading rate effect of mechanical properties of coal and provide a reference for controlling the stability of the residual coal pillar.

\section{Introduction}

As a natural disaster, instability of coal pillar often poses a serious threat to safe and efficient mining, especially in room-pillar mining $[1,2]$. There are a large number of residual coal pillars left in room-pillar re-mined panels, and these pillars play an essential role in the stability of the working face [3]. Therefore, it is very important to study the instability and failure mechanism of coal pillars for the safe mining of room-pillar residual coal.

In room-pillar mining, the main parameters affecting the stability of coal pillars are pillar material, pillar width, pillar height, and roof strength $[4,5]$. Scholars at home and abroad have done a lot of research in this field. Yu et al. studied the influence of geometric parameters of mining on the stability of pillars by numerical simulation [6]. Zhou et al. studied the influence of backfilling paste on the stability of pillars and obtained the mechanism of the influence of backfilling paste on the stability of residual pillars [7]. Cording observed the pillars of shale reservoirs and concluded that the instability of pillars is mainly caused by the combination of stress slabbing and slaking on the surface of pillars [8]. Based on the energy catastrophe theory, Zhou et al. studied the influence of the constitutive equation and shape of the pillar in the goaf of gypsum mine on its stability and put forward the necessary and sufficient conditions for the instability of the pillar [9]. Zhou et al. analyzed the influence of geometric parameters in the roof-pillar support system and obtained the classification standard of goaf stability $[10,11]$. Vida studied the influence of pillar width on pillar stability [12]. Zhou et al. studied the influence of dynamic load on the stability of adjacent coal pillars during excavation by the numerical simulation method [13]. Obviously, in the past, scholars have conducted in-depth research on pillars. 
However, with the increase in mining intensity, the rate of stress adjustment in coal pillar will increase significantly [14]. Practice and research show that the increase in advancing speed of working face will affect the stress environment of coal and rock, change the law of deformation and failure of coal and rock, and increase the difficulty of mining $[15,16]$. Therefore, the study of coal mechanical response under different loading rates will have important theoretical guidance and practical significance for ensuring the stability of pillars.

In the study of loading rate on rock mechanics, most scholars believe that rock strength increases with the increase in loading rate [17-21]. For example, Alam et al. believed that strength, modulus of elasticity, and ultimate strain increased with the increase in loading rate [22-24]. For soft rock, previous tests show that rock strength is not sensitive to loading rate. Liang's results show that the effect of loading rate on salt rock is very weak [25]. In addition, Wasantha et al. believed that the strength of specimens with larger particle size would increase at a low loading rate [26]. Similarly, the effect of loading rate on the mechanical properties of coal samples has not been clearly concluded [27, 28].

In addition to mechanical properties and failure characteristics, acoustic emission (AE) is also used as one of the characteristic parameters to study the mechanical response of loading rate to coal and rock. Because of the instability of the coal pillar in the process, the damage inside the coal pillar will determine the form of macrodamage. Previous scholars have studied the effect of rock types and loading paths on crack propagation through in situ emission but did not consider the effect of loading rate on crack propagation $[29,30]$. This is the main content of this paper.

The main purpose of this paper is to study the effects of loading rate on the deformation and mechanical characteristics of coal samples through experiments. Furthermore, the internal mechanism of failure strength and failure modes of specimens are explained by means of AE from the microcosmic point of view of crack propagation.

\section{Methodology}

The strain rate is the strain that occurs in the sample per unit time. According to the type of loading test machine and the mechanical state of rock, strain rate can be divided into creep, static/quasistatic, quasidynamic, dynamic, impact, and so on, as shown in Figure 1 [31-33]. According to Li's research results, the loading rate in quasistatic range is studied in this paper.

In this paper, the stress state of coal pillar is simplified as a uniaxial compression model $[34,35]$. Therefore, the influence of mining rate on the stability of coal pillar can be transformed into the influence of strain rate on coal sample under uniaxial compression [36]. The schematic diagram of the model is shown in Figure 2.

2.1. Subsection. All testing was carried out on coal specimens prepared from block samples which were taken from the Baigou Coal Mine 3\# Coal, located in Shanxi Province. The rock blocks were picked up just after the excavation and transported to the laboratory, where the samples $(\Phi 25 \times 50 \mathrm{~mm})$ were cored to ensure that the nonparallelism of the top and bottom surfaces is less than $0.05 \mathrm{~mm}$ and that the surface evenness is less than $0.02 \mathrm{~mm}$ according to specifications [37]. A total of 12 samples were prepared, four groups (each group contained 3 samples), and numbered separately. The loading conditions of each specimen are shown in Table 1.

2.2. Test Method. The experimental system consists of an axially loaded subsystem and an AE monitoring subsystem, as shown in Figure 3.

In the experiment, the variable is the loading rate, and the collected data are mainly load, displacement, and AE. The loading system of this experiment is MTS815 hydraulic servo testing machine. To study the effect of loading rate on samples at different scales, the loading conditions in this experiment were displacement loading, which were $5 \times 10^{-7} \mathrm{~m} / \mathrm{s}, 5 \times 10^{-6} \mathrm{~m} / \mathrm{s}, 1.7 \times 10^{-6} \mathrm{~m} / \mathrm{s}$, and $5 \times 10^{-5} \mathrm{~m} / \mathrm{s}$, respectively. In order to ensure the accuracy and reliability of $\mathrm{AE}$ data, the sample and AE probe are coated with coupling agent and fixed together with white tape. Before the experiment, the reliability of the AE probe is tested by tapping on the sample. In order to make the AE data correspond to the stress data in time, the AE data will be collected at the beginning of the experiment when the stress-strain curve appears on the loading acquisition system. The above experimental methods are sufficient to obtain the mechanical characteristics and emission distribution of samples under different loading rates.

\section{Results}

3.1. Test Results. Uniaxial compression tests with different loading rates were performed on the samples, and the results are shown in Figure 4.

It can be seen from Figure 4 that the stress-strain curves of coal under different loading rates have a compaction process with the strain of 0.01 . This shows that there are a lot of microcracks in the sample before loading, and the microcracks at different loading rates have enough time to be closed. At the junction of elastic stage and compaction stage, the greater the loading rate is, the smaller the stress adjustment is. At the junction of the elastic stage and the compaction stage, the stress adjustment at the middle of two loading rates is larger than that at the high and low loading rates. At the stage of elastic and crack stable propagation, the stress-strain curves at different loading rates basically remain unchanged. In the stage of unstable fracture propagation, the stress-strain curve is adjusted most obviously when the loading rate is $5 \times 10^{-7} \mathrm{~m} / \mathrm{s}$. However, there is no obvious stress adjustment at the other three loading rates. On the whole, with the increase in loading rate, the strength of specimens first decreases and then increases. However, when the loading rate is $5 \times 10^{-7} \mathrm{~m} / \mathrm{s}$, the strength and strain of the specimens increase abnormally. This indicates that the fracture process of the specimens at the loading rate of 


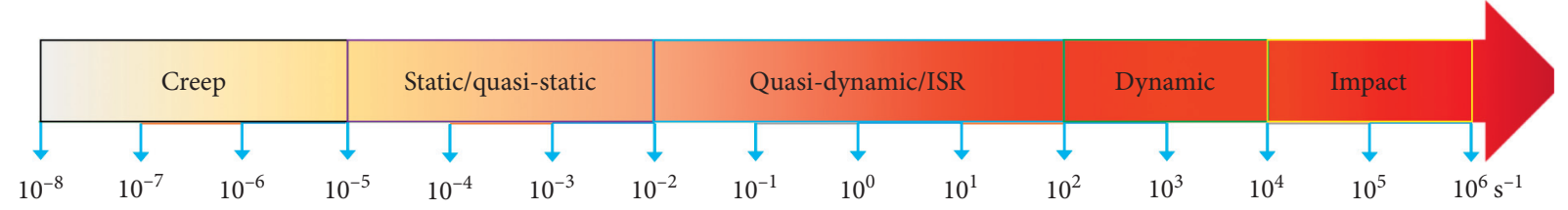

FIgURE 1: Stress state of rocks under different strain rates.

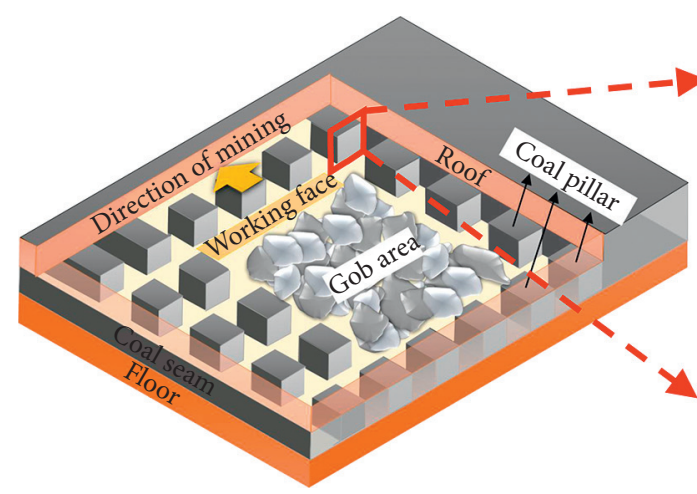

(a)

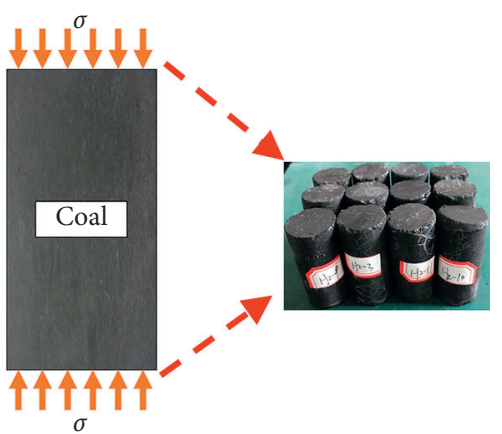

(b)

(c)

Figure 2: A schematic of room and pillar recovery in residual coal seam: (a) plane view of room and pillar recovery in residual coal seam; (b) the simplified model of coal pillar stress condition; (c) coal samples.

TABLE 1: Loading conditions of samples.

\begin{tabular}{lc}
\hline Coal samples & Loading rates $(\mathrm{m} / \mathrm{s})$ \\
\hline H3-1, H3-2, H3-3 & $5 \times 10^{-7}$ \\
H3-4, H3-5, H3-6 & $5 \times 10^{-6}$ \\
H3-7, H3-8, H3-9 & $1.7 \times 10^{-5}$ \\
H3-10, H3-11, H3-12 & $5 \times 10^{-5}$ \\
\hline
\end{tabular}

$5 \times 10^{-7} \mathrm{~m} / \mathrm{s}$ is different from that at other three loading rates.

As shown in Figure 5, with the decrease in loading rate, both ultimate stress and ultimate strain show a decreasing trend. However, when the loading rate is $5 \times 10^{-7} \mathrm{~m} / \mathrm{s}$, the ultimate stress and strain increase, as shown in Figures 5(a) and 5(c). There is no direct relationship between the elastic modulus and loading rate, and the failure time shows a negative exponential relationship with the decrease in loading rate, as shown in Figures 5(b) and 5(d).

3.2. Acoustic Emission. The strain energy released by the generation and expansion of cracks in the process of coal deformation will propagate outward in the form of elastic waves, which is called acoustic emission (AE). So, AE can reflect the evolution process of rock damage in time. The Kaiser effect is the memory effect of material AE on its stress process. In other words, when the stress exceeds the maximum stress before loading, a large amount of AE occurs in rock. In this paper, the Kaiser point is determined by finding the sudden change point in the relationship between the number of $\mathrm{AE}$ counts and the time stress.

The following can be seen from Figure 6. (1) The energy and counts of $\mathrm{AE}$ decrease with the increase in loading rate, which indicates that within the scope of the study, when the loading rate is higher, the cracks in the specimen will also develop worse, and the internal integrity of the sample is the better. (2) With the increase in loading rate, the attenuation gradient of AE energy and quantity is different, that is, the energy per unit number of AE counts is not equal. This shows that the size of crack propagating is different under different loading rates.

According to the number of AE counts and energy, the process of rock compression failure can be divided into four stages: crack closure, elastic deformation, stable crack propagation, and unstable crack propagation [38], as shown in Figure 7. According to the analysis of Figure 7, the $\mathrm{AE}$ characteristics of the samples have the following characteristics: (1) with the increase in loading rate, the magnitude and the number of stress adjustment before peak value decrease gradually; (2) with the increase in loading rate, the maximum number of AE counts and energy moves from the peak value of residual stress to the peak value of stress; (3) with the increase in loading rate, AE evolves from multipeak to single-peak, from continuous dense to discrete catastrophic; (4) with the increase in loading rate, the increasing rate peak of the total number of $\mathrm{AE}$ counts and energy is closer to the peak stress; and (5) with the increase in loading rate, the stress at the Kaiser point of AE increases gradually.

After analysis, the above characteristics are mainly due to the following reasons. Coal is a kind of rock with loose structure and wide distribution of microfissures. Experiments show that in the stage of crack closure, microcracks begin to close, and no new cracks occur at the same time. Therefore, there is no significant change in the AE signal at this stage. 


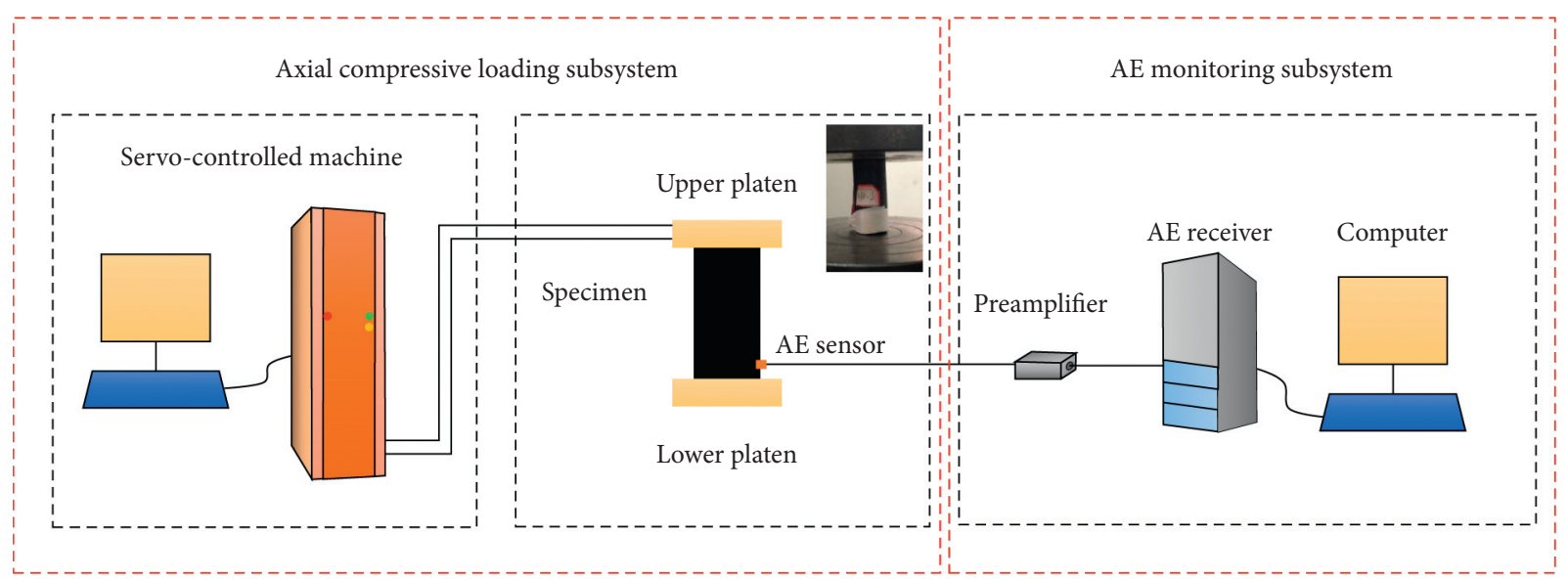

Figure 3: Schematic diagram of the test system.

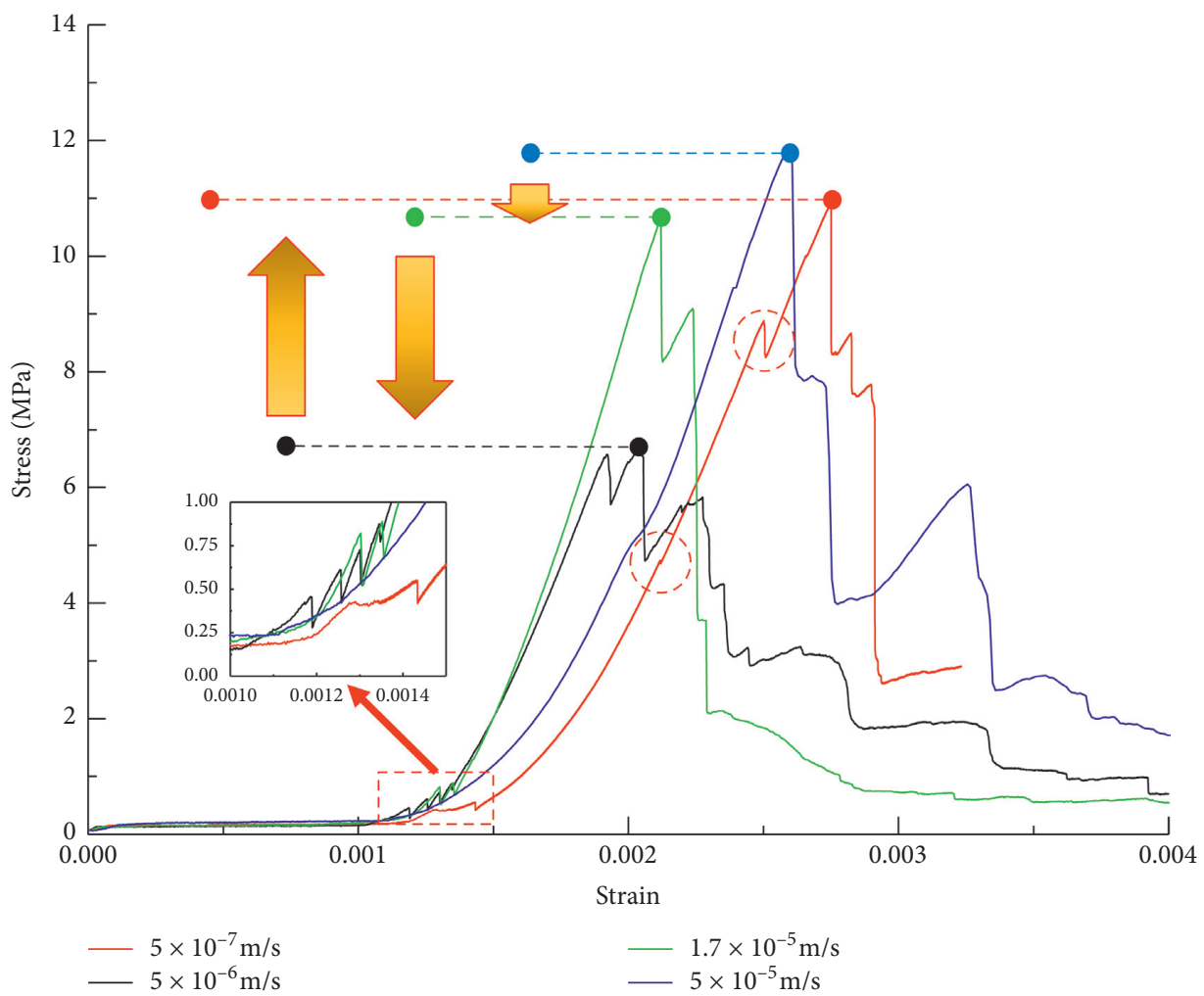

FIgURE 4: Stress-strain curve under different loading rates.

In the elastic deformation stage, the number of $\mathrm{AE}$ counts and the energy values has no significant changes at different loading rates, which is consistent with previous studies. At the same time, there is a phenomenon of stress adjustment but no obvious AE in samples. Moreover, with the increase in loading rate, the magnitude and the number of stress adjustments become smaller and smaller. This indicates that the stress adjustment at this stage is due to the elastic deformation caused by the inhomogeneity in the specimen, rather than new damage. At the later stage of elastic stage, microcracks begin to crack slowly and the number of $\mathrm{AE}$ begins to increase. In addition, the higher the loading rate is, the more compact the specimen will be pressed at this stage and the greater the stress of the regenerated crack will be. So, the Kaiser point moved back.

In the stage of stable crack propagation, the smaller the loading rate is, the smaller the increment of internal stress in coal samples will be. Therefore, the microcracks in the sample can be fully expanded. In contrast, the larger the loading rate is, the less the microcracks will expand. With the continuation of loading, the development of microcracks at different loading rates will be different at this stage. 


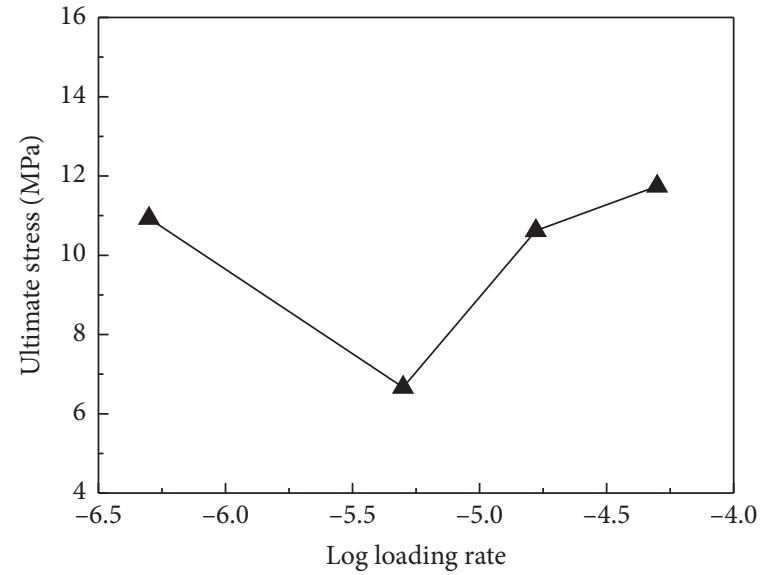

(a)

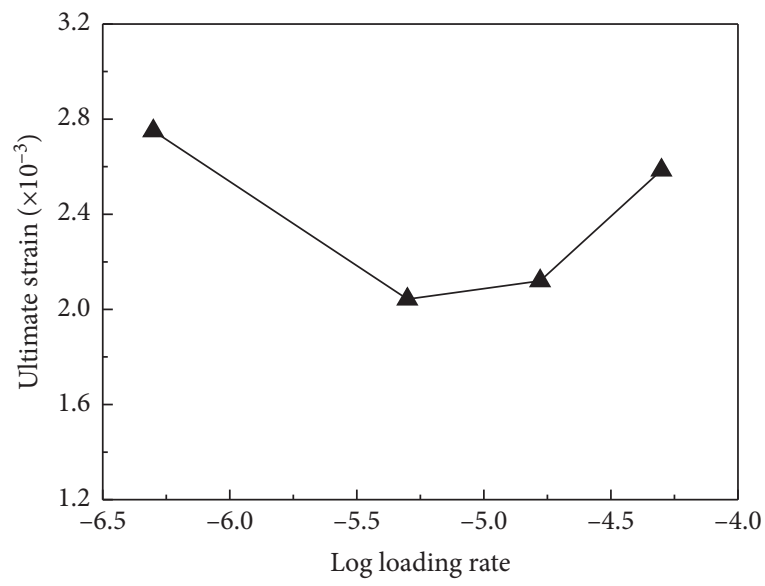

(c)

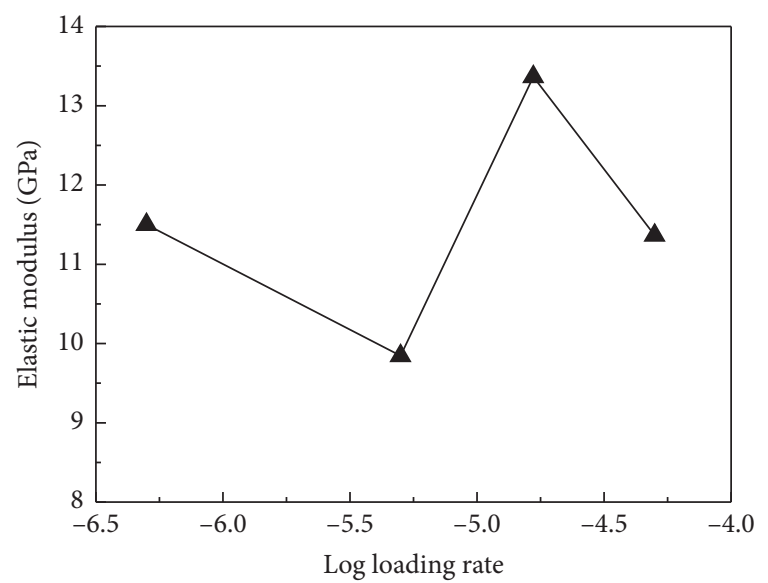

(b)

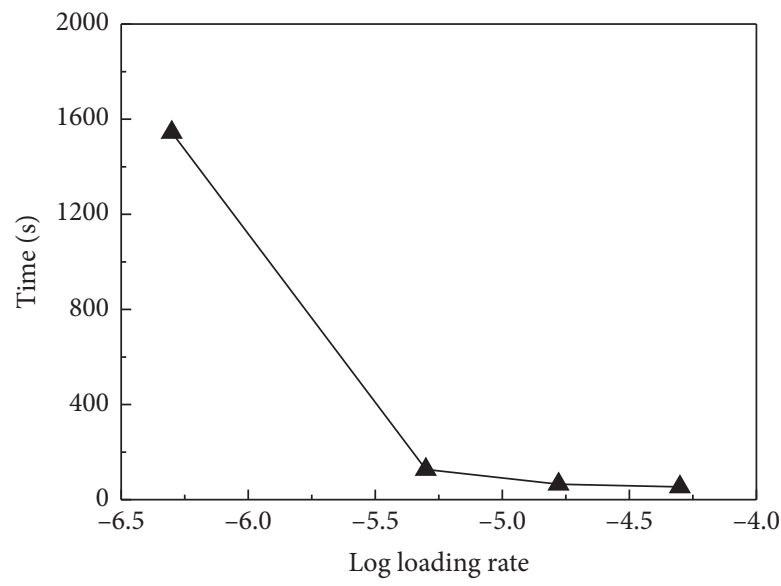

(d)

FIGURE 5: Mechanical characteristic curves under different loading rates: (a) the relationship between ultimate stress and loading rate; (b) the relationship between elastic modulus and loading rate; (c) the relationship between ultimate strain and loading rate; (d) the relationship between time and loading rate.

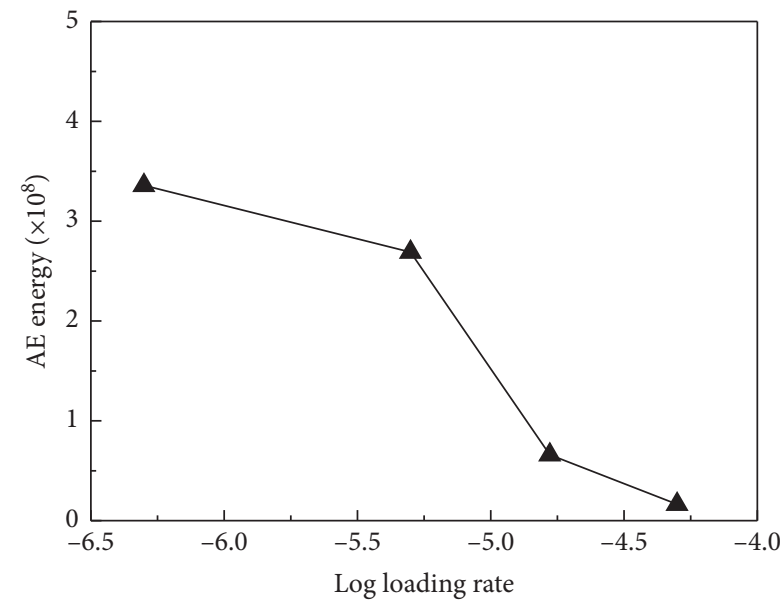

(a)

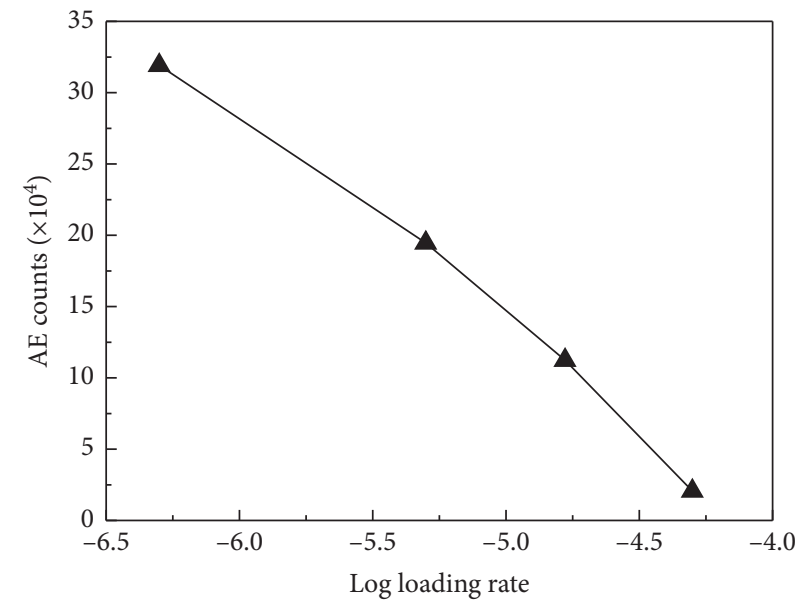

(b)

FIgURE 6: The cumulative AE energy and counts curves under different loading rates: (a) the relationship between AE energy and loading rate; (b) the relationship between $\mathrm{AE}$ counts and loading rate. 


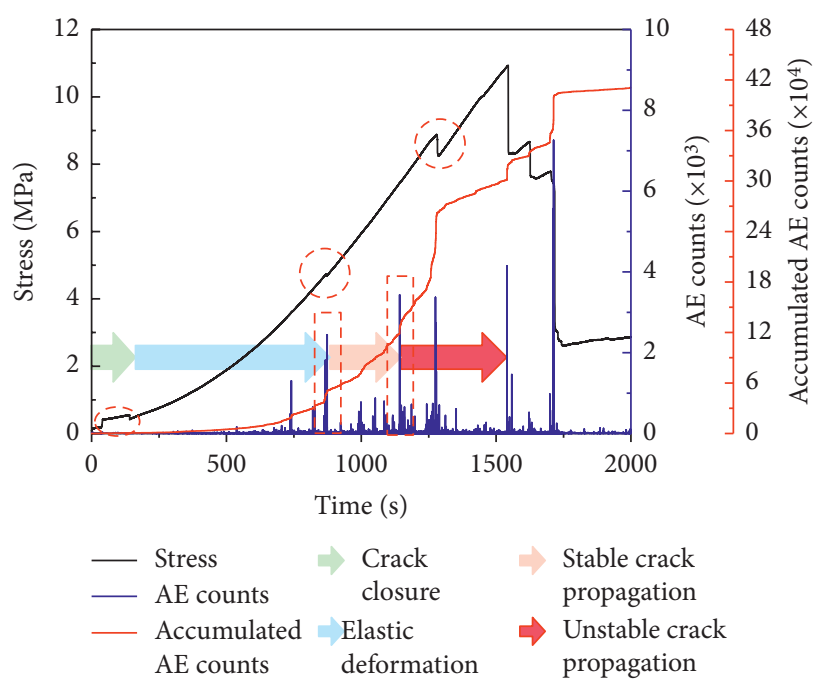

(a)

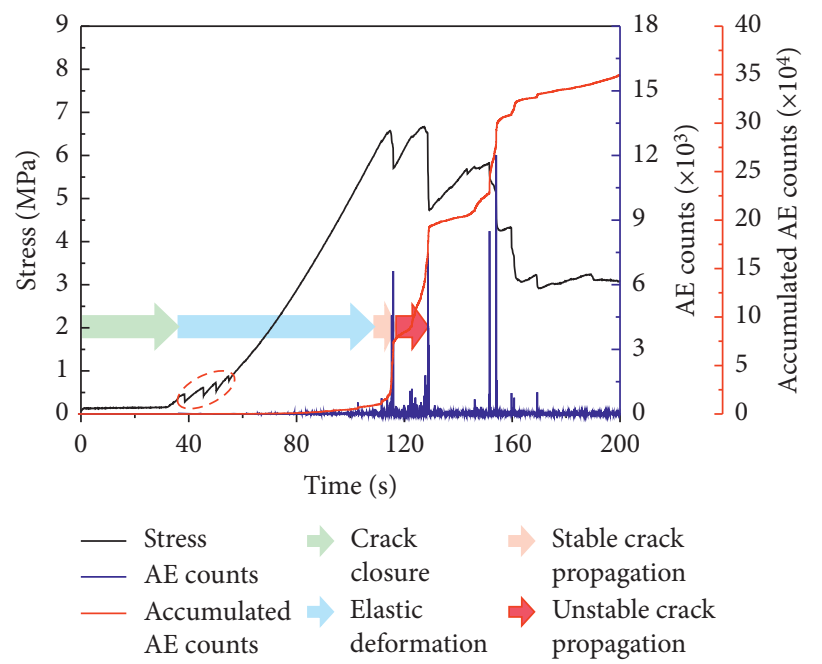

(c)

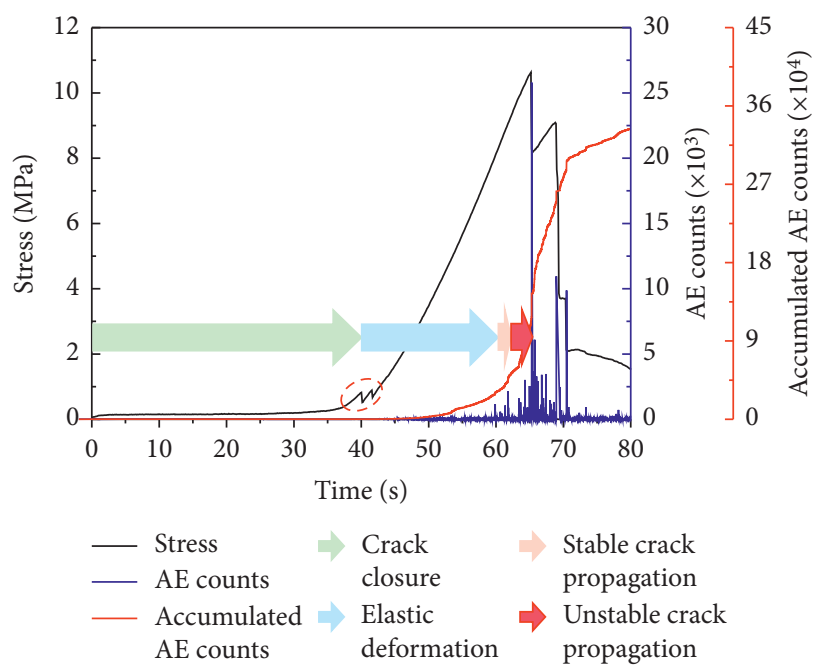

(e)

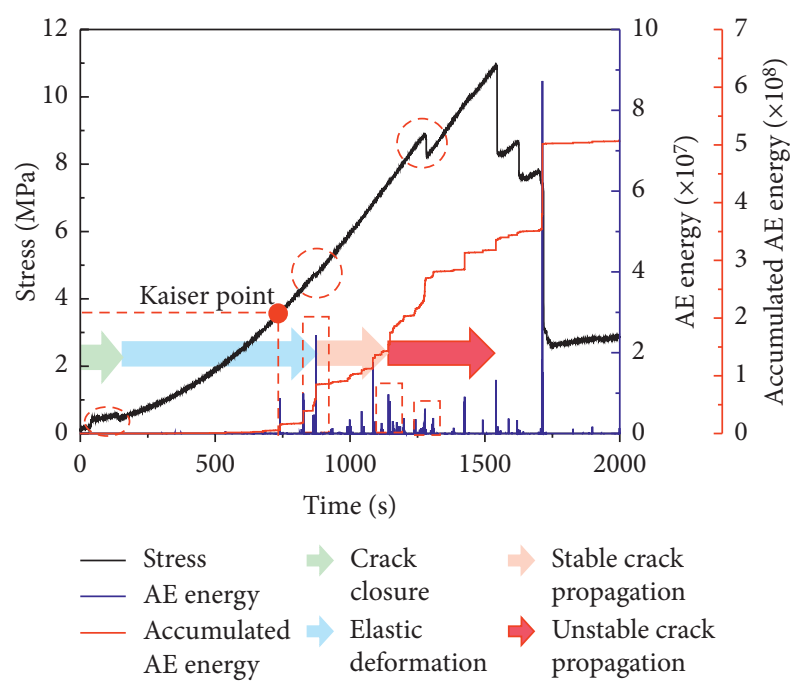

(b)

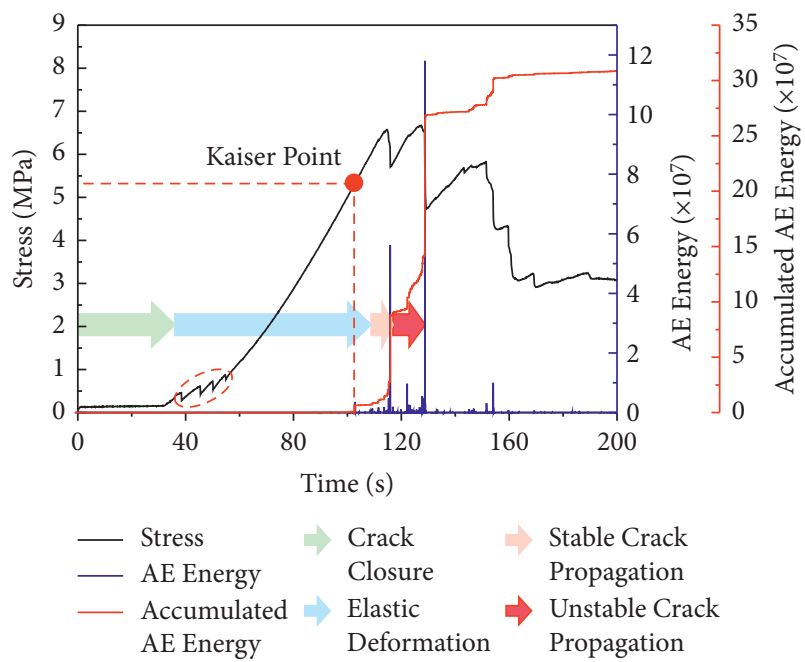

(d)

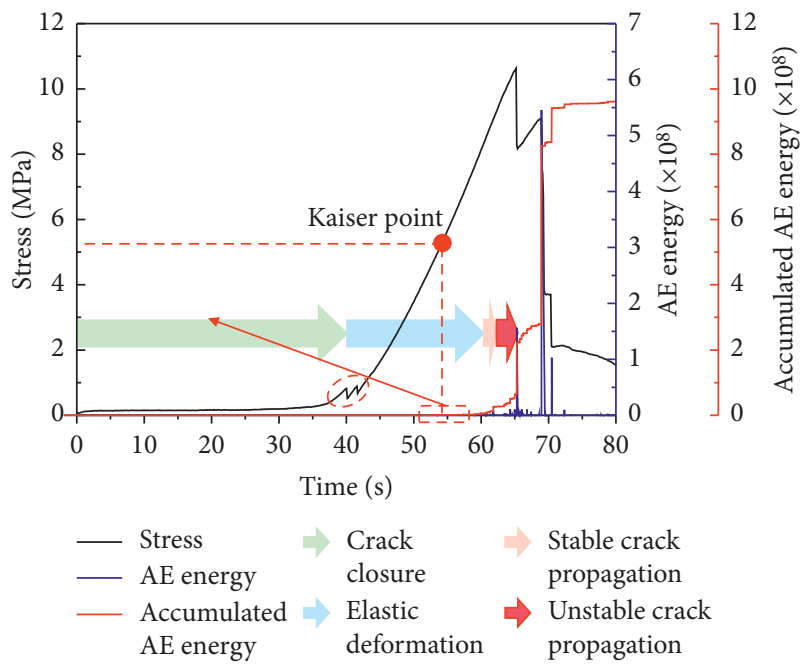

(f)

Figure 7: Continued. 


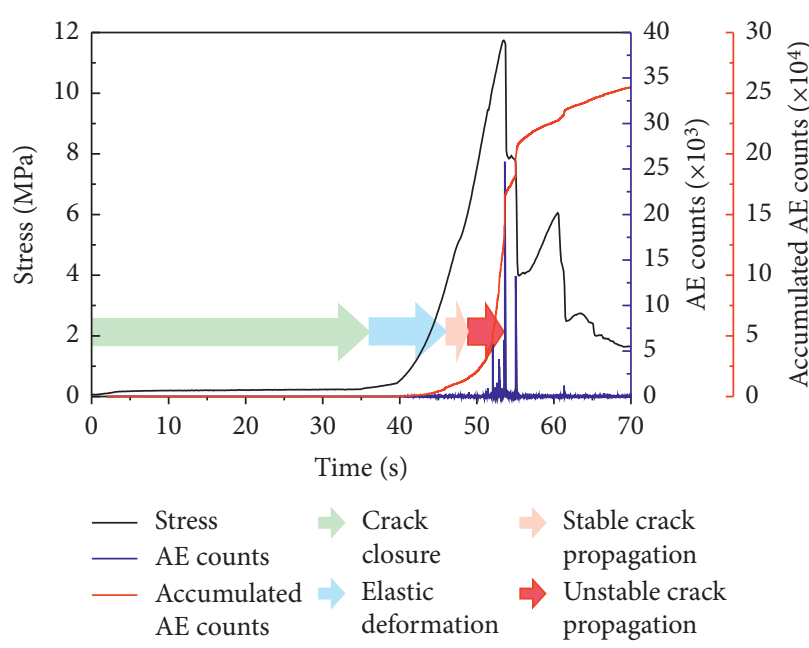

(g)

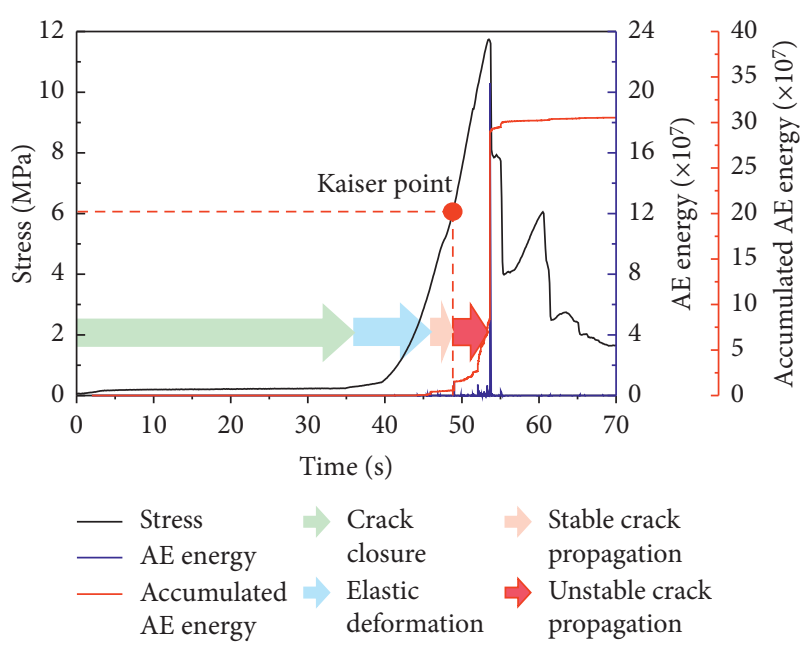

(h)

Figure 7: AE counts-AE energy-stress-time curves under different loading rates: (a) AE counts-stress-time curves when the loading rate is $5 \times 10^{-7} \mathrm{~m} / \mathrm{s}$; (b) AE energy-stress-time curves when the loading rate is $5 \times 10^{-7} \mathrm{~m} / \mathrm{s}$; (c) AE counts-stress-time curves when the loading rate is $5 \times 10^{-6} \mathrm{~m} / \mathrm{s}$; (d) AE energy-stress-time curves when the loading rate is $5 \times 10^{-6} \mathrm{~m} / \mathrm{s}$; (e) AE counts-stress-time curves when the loading rate is $1.7 \times 10^{-5} \mathrm{~m} / \mathrm{s}$; (f) AE energy-stress-time curves when the loading rate is $1.7 \times 10^{-5} \mathrm{~m} / \mathrm{s} ;(\mathrm{g})$ AE counts-stress-time curves when the loading rate is $5 \times 10^{-5} \mathrm{~m} / \mathrm{s}$; (h) AE energy-stress-time curves when the loading rate is $5 \times 10^{-5} \mathrm{~m} / \mathrm{s}$.

Therefore, with the increase in loading rate, AE evolves from multipeak to single-peak, from continuous dense to discrete catastrophe.

In the stage of unstable crack propagation, microcracks continue to expand and macrocracks continue to form. When macrocracks penetrate each other, the specimen will be destroyed. With the increase in loading rate, the macrocrack of the specimen is relatively single. When the specimen is destroyed, the residual bearing capacity is lost. However, when the loading rate is small, the macroscopic cracks are complex. When the specimen is destroyed, it still has residual bearing capacity. That is to say, the larger the loading rate is, the more sudden the failure is, which means that the closer the peak value of fracture increment is to the peak value of stress. Therefore, with the increase in loading rate, the incremental peak of the total number of AE counts and energy is closer to the peak stress.

3.3. Failure Mode. Past studies have shown that the failure modes of coal pillars are mainly divided into four types [39], as shown in Figure 8. In this experiment, the failure modes of specimens under different loading rates can be seen in Figure 9. From Figure 9, it can be seen that with the increase in loading rate, the order of fracture modes of specimens is breakage-tension failure, compression-shear failure, and single shear failure. With the increase in loading rate, the evolution order of fracture modes of specimens is as shown in Figures 8(a)-8(c). The different failure modes of specimens under different loading rates are mainly due to the differential development of microcracks in the stage of unstable crack propagation. With the increase in loading rate, the stress increases rapidly and the microcracks develop less and less. The failure mode of specimens is single shear failure. When the loading rate is low, the microcracks are abundant in the specimen. When the specimen reaches the failure condition, there are many cracks in the specimen, which results in tension failure.

\section{Discussion}

4.1. Failure Mechanism. Previous studies have shown that the adjustment of load-bearing structure during loading will affect the development of microcracks and then affect the strength of specimens $[39,40]$. In this paper, in order to explain the mechanism of the effect of loading rate on the mechanical and deformation characteristics of specimens, "Weak Structure" (WS) and "Hard Bearing Structure" (HBS) are introduced. It is assumed that the specimen is mainly composed of two kinds of structures, i.e., WS and HBS. WS mainly plays the role of adjusting the internal stress of the specimen, and HBS determines the strength and failure mode of the specimen. From the plane view, the weak structure is surrounded by the hard structure, as shown in Figure 10. The green vertical line in Figure 10 represents the HBS and the yellow vertical line represents the WS.

At the initial stage of loading, there is structural heterogeneity in the specimen, which will be expressed by the length of different structures. When the specimen is loaded, the compaction stage is an adaptive adjustment process of the porosity of the specimen, which has nothing to do with the structure. At this time, the sample structure did not play a major role in bearing capacity. After further compression deformation, a small part of HBS and most of WS of the specimen contact with the indenter on the testing machine and produce deformation. During the whole elastic deformation stage, the two structures of the specimens did not break.

When the loading continues, the specimen enters the stable crack propagation and unstable crack propagation 


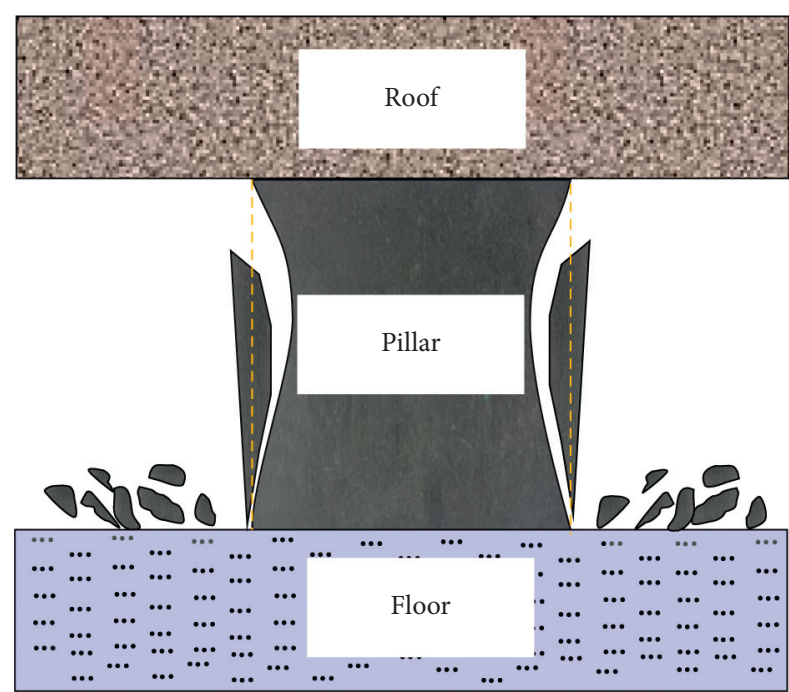

(a)

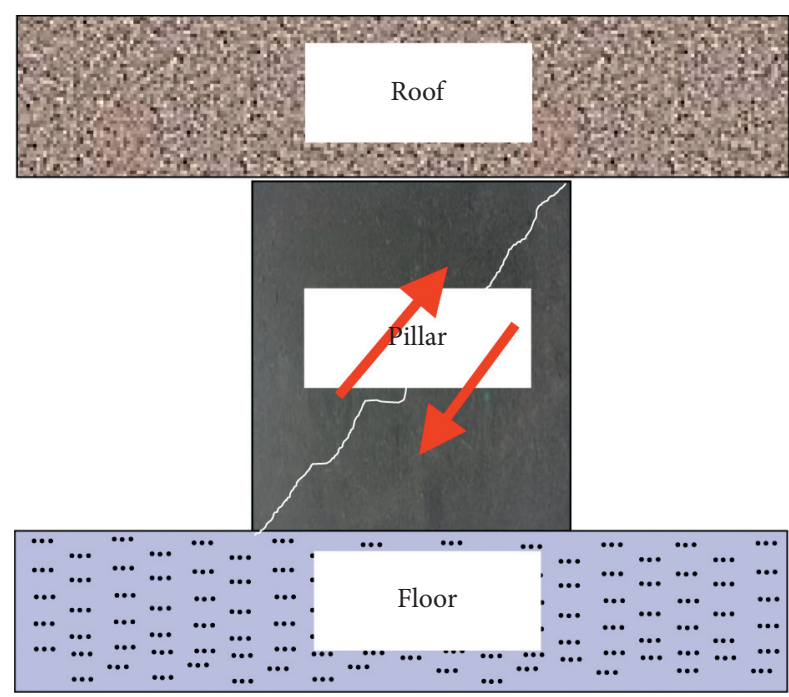

(c)

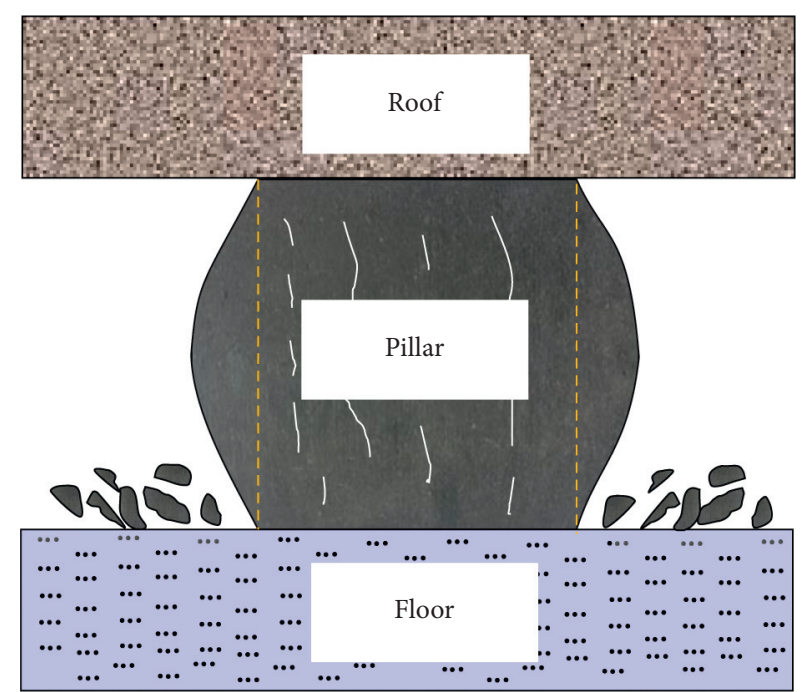

(b)

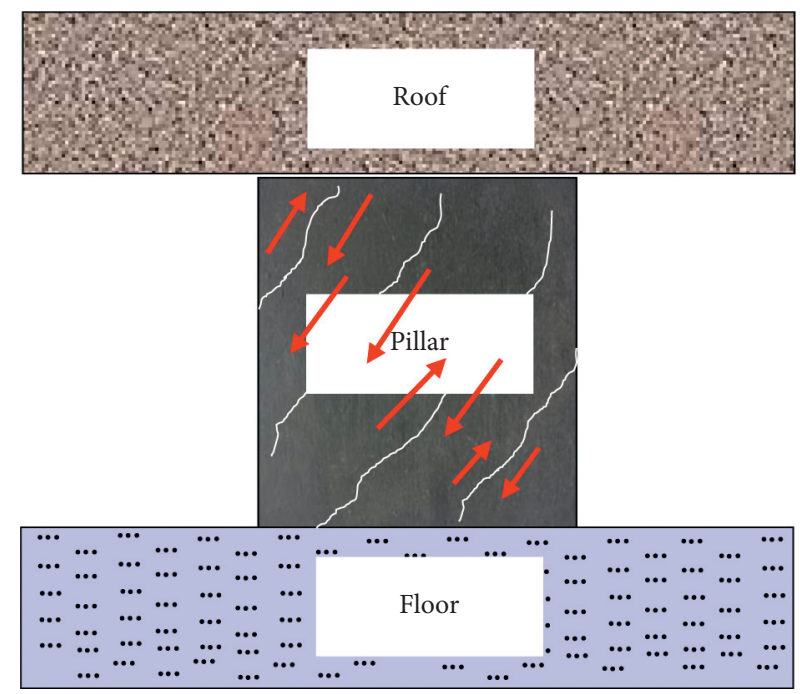

(d)

FIgURE 8: Diagram of pillar failure modes: (a) lateral spalling; (b) splitting inside pillar; (c) compression-shear failure; (d) joint failure.

stage. When the loading rate is small, the increase rate of stress in the specimen is small, so WS will be fully destroyed and adjusted. After continually experiencing the process of breaking-compaction-breaking, a number of HBS with uneven forces are adjusted to the optimum stress state inside the specimen, which leads to the increase in the effective bearing area on the cross section of the specimen. The strength of the specimens increases because of the decrease in "damage quantity." At the same time, due to the failure of many WS in samples, there are many internal cracks. When the specimen is destroyed, the fracture forms are complex and varied, as shown in Figures 9(a) and 11(a).

With the increase in loading rate, the failure time of specimen decreases and the number of WS decreases, which leads to inadequate stress adjustment of HBS. On the one hand, with the increase in loading speed, the number of damages of WS decreases, which is shown by the decrease in damage amount and the increase in apparent strength. On the other hand, the stress concentration of the HBS can easily lead to the breakage of the bearing structure, resulting in the decrease in the apparent strength and the compression-shear failure mode of the specimen. Therefore, the mechanical properties of the specimens show that the strength of the specimens decreases with the increase in loading rate, as shown in Figure 11(c).

The loading rate continues to increase, and WS hardly breaks. At this time, although the stress state of the HBS is not optimized, its surrounding structure maintains its integrity and changes from the adjusted biaxial force to the triaxial force. Therefore, with the increase in loading rate, the strength of specimens will continue to increase, and the failure mode presents shear failure, as shown in Figures 9(d) and 11(b). Thus, in the whole loading range, the strength of the specimen decreases first and then increases.

Therefore, WS and HBS play an important role in the failure process of specimens. The effect of WS on the damage 


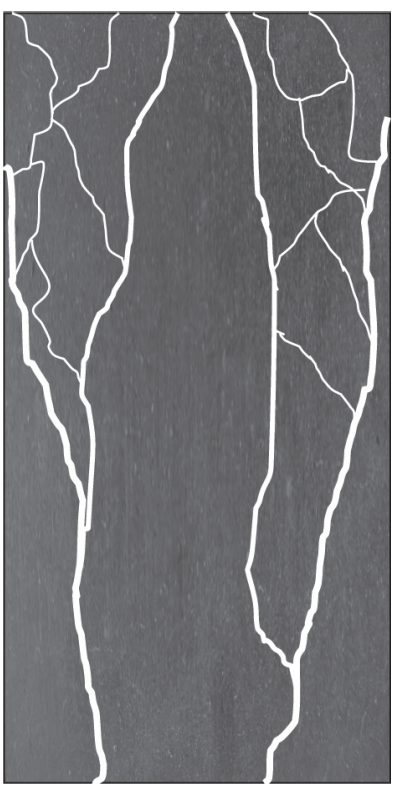

(a)

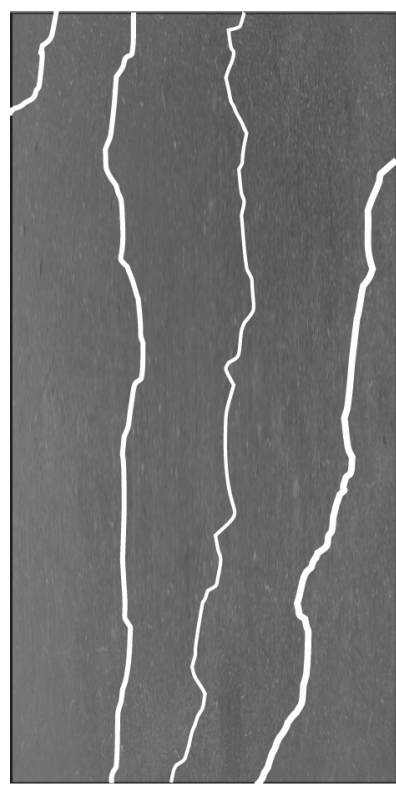

(b)

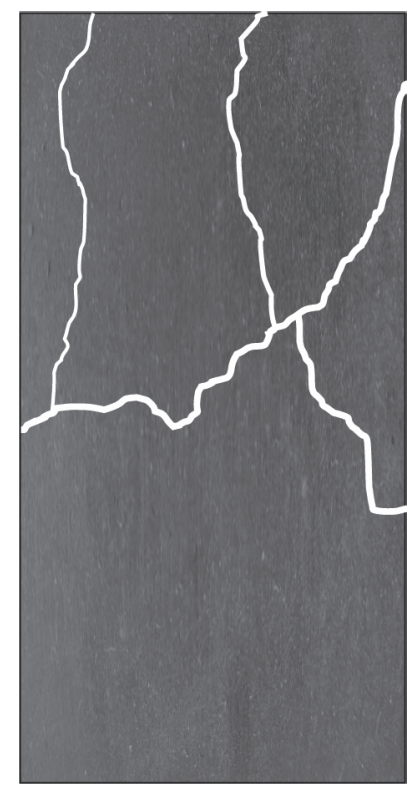

(c)

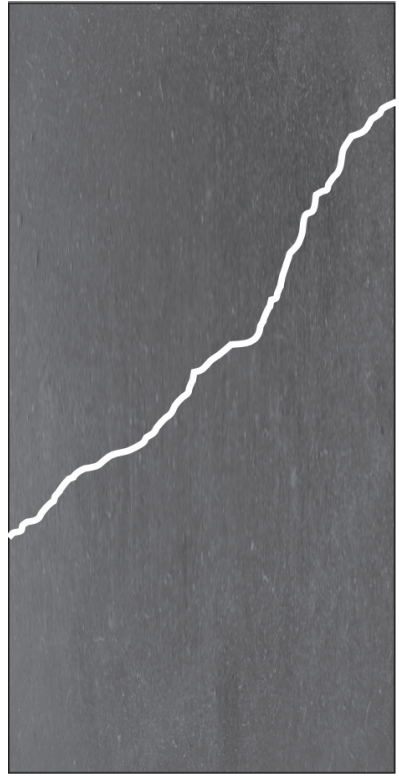

(d)

Figure 9: Failure modes of samples under different loading rates: (a) the loading rate is $5 \times 10^{-7} \mathrm{~m} / \mathrm{s}$; (b) the loading rate is $5 \times 10^{-6} \mathrm{~m} / \mathrm{s}$; (c) the loading rate is $1.7 \times 10^{-5} \mathrm{~m} / \mathrm{s}$; (d) the loading rate is $5 \times 10^{-5} \mathrm{~m} / \mathrm{s}$.

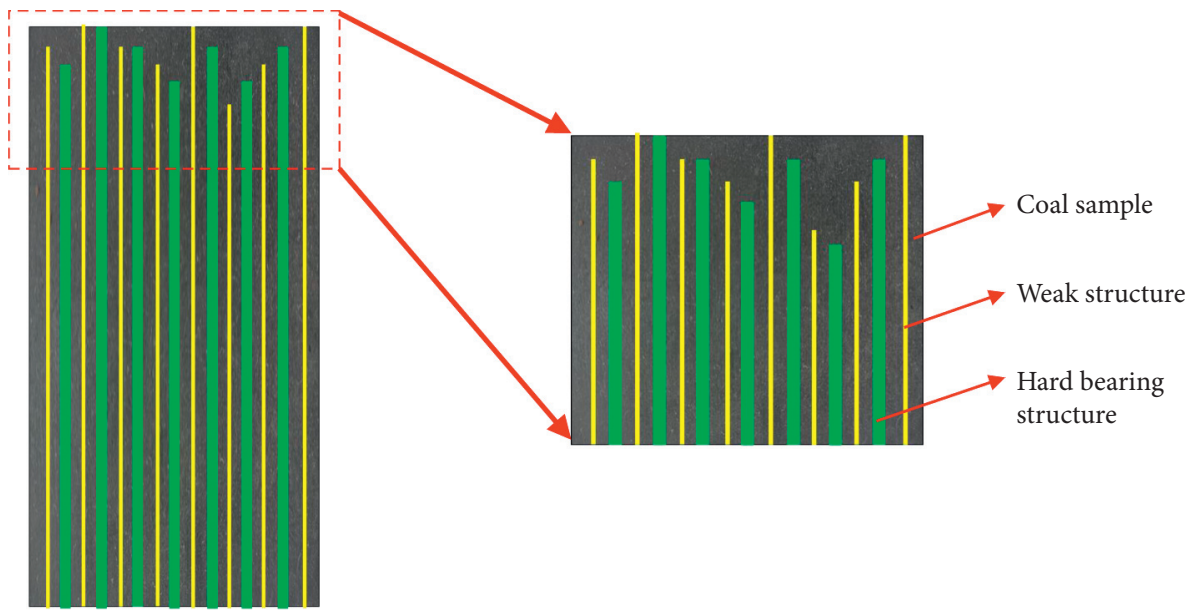

FIGURE 10: Failure model of sample structure.

of specimens is as follows. On the one hand, the internal WS is adjusted to optimize the loading conditions of the HBS and increases the effective bearing area of the structure. On the other hand, the fracture of the WS will also cause damage in the specimen, thus reducing the effective bearing area. The strength of HBS specimens plays a decisive role and controls the failure mode of the specimens.

4.2. On-Site Control Measures. In previous studies, laboratory AE signals can be used to represent microseismic signals in the field [41]. From the conclusion of this paper, it can be concluded that in order to provide early warning information and control measures for the stability of field coal pillars, it is necessary to detect the stress, roof subsidence, and microseismic signals in the pillars during the re-mining of room-pillar residual coal. When the stress in the coal pillar increases slowly and the roof subsides slowly, the microseismic signal after filtering noise in the coal pillar is continuously observed. When the stress in the coal pillar increases slowly and the roof subsides slowly, the microseismic signal after filtering noise in the coal pillar is continuously observed. If the magnitude of the microseismic signal is smaller than that of the failure signal and presents a continuous distribution, then it can be determined that the advancing speed of the working face should belong to a slower range at this time. If the magnitude of the microseismic signal is smaller than that of the failure signal and 


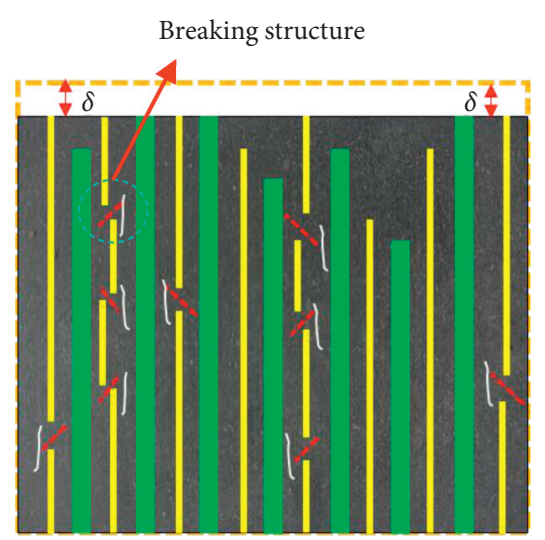

(a)

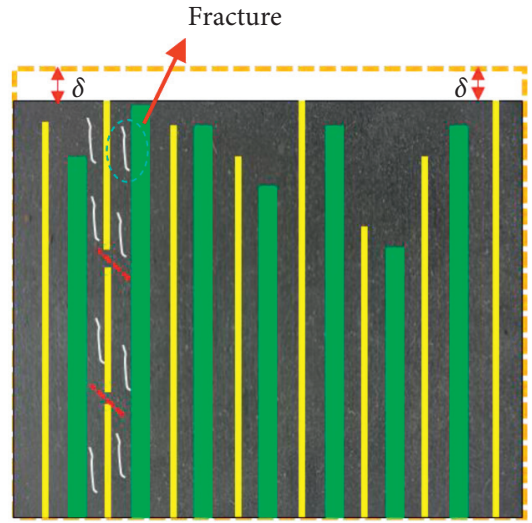

(b)

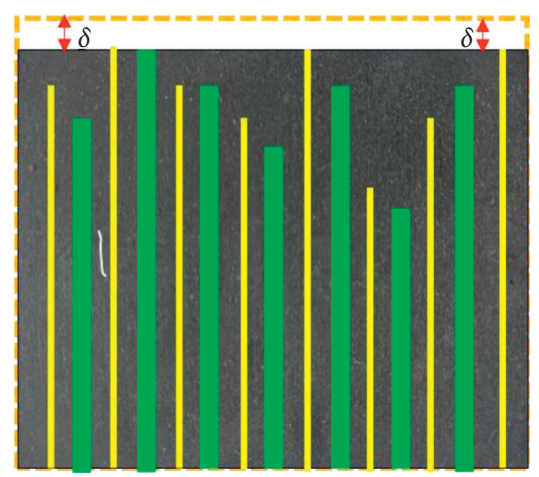

(c)

FIGURE 11: Failure structure of samples under different loading rates: (a) the loading rate is $5 \times 10^{-7} \mathrm{~m} / \mathrm{s}$; (b) the loading rate is $5 \times 10^{-5} \mathrm{~m} / \mathrm{s}$; (c) other loading rates.

shows a sudden change distribution, then it can be determined that the advancing speed of the working face should be between slower and faster at this time. When the stress increase speed and roof subsidence speed are severe, researchers should continuously observe the microseismic signal after noise removal in the coal pillar. If the magnitude of the microseismic signal is much smaller than that of the failure signal, the velocity of the working face is determined to be in a fast range. Therefore, through the comprehensive analysis of the three different informations, the early warning and control of the stability of coal pillars can be realized.

(1) If the advancing speed of the working face is slower, the signals satisfy the characteristics of slower loading rate. This shows that the peak strength and residual strength of the coal pillar are large, and the coal pillar is relatively broken. In order to increase cohesion and integrity of coal pillars and enhance residual support capacity of coal pillars, bolt-mesh combined support should be adopted.

(2) When the advancing speed of the working face is very fast, the stress of the coal pillar remains unchanged, and the microseismic signal basically does not exist. At this time, attention should be paid to the prevention of coal burst caused by the sudden destruction of coal pillars. On the one hand, to protect coal pillars, bolting force should be increased, and grouting process should be increased, so as to improve the cohesion and strength of coal pillars. On the other hand, for other coal pillars, pressure can be relieved by drilling holes to increase the fracture volume of coal pillars. The influence of faster mining rate on coal pillar is transferred to that of normal rate.

(3) In other cases, the strength of coal pillar is low, and the failure mode may be complex compression-shear failure. Protective measures should be taken into consideration in the light of the actual use of coal pillars.
In summary, in order to ensure the stability of coal pillar in working face, the mining rate of working face is not necessarily the slower the better. The optimum mining rate should be determined according to the on-site detection information and specific conditions.

\section{Conclusions}

(1) The stress adjustment is obviously influenced by the loading rate. If the loading rate is lower, the stress adjustment is earlier.

(2) With the increase in loading rate, the magnitude of stress adjustment before peak value decreases gradually, and the number of adjustment decreases gradually; the maximum number of $\mathrm{AE}$ counts and energy moves from the peak value of residual stress to the peak value of stress. The increase rate peak of the total number of AE counts and total energy is closer to the peak stress, and the trend of AE evolution is from multipeak to single-peak, from continuous intensive to discrete catastrophic; the failure trend of the specimens is presented as follows: breakage-tension failure, compression-shear failure, and single shear failure.

(3) The failure mechanism of the specimens is determined by both WS and HBS. With the increase in loading rate, the effect of WS decreases gradually. HBS mainly determines the strength and failure mode of specimens.

(4) The failure strength and mode of coal pillars in situ are initially identified by data and experimental results of field detection. When the advancing speed of the working face is small, the cohesion and integrity of the coal pillar should be increased and the residual supporting capacity of the coal pillar should be improved. On the one hand, when the advancing speed of working face increases, the strength of safety coal pillars should be improved. On the other hand, for other coal pillars, the influence range of velocity should be transferred. 


\section{Data Availability}

The data used to support the findings of this study are available from the corresponding author upon request.

\section{Conflicts of Interest}

The authors declare that they have no conflicts of interest.

\section{Acknowledgments}

This research was funded by the High-Tech Research and Development Foundation of LvLiang City "3D accurate technique modeling for transparent working face based on ultrasonic detection" (grant no. 2020GxZDYF22).

\section{References}

[1] C. Mark, Overview of Ground Control Research for Underground Coal Mines in the United States, National Institute for Occupational Safety and Health, Pittsburgh Research Laboratory, Pittsburgh, PA, USA, 2001.

[2] C. Mark, F. E. Chase, and R. K. Zipf, Preventing Massive Pillar Collapses in Coal Mines, US Department of Health and Human Services, Public Health Service Centers, Washington, DC, USA, 1997.

[3] J.-X. Zhang, P. Huang, Q. Zhang, M. Li, and Z.-W. Chen, "Stability and control of room mining coal pillars-taking room mining coal pillars of solid backfill recovery as an example," Journal of Central South University, vol. 24, no. 5, pp. 1121-1132, 2017.

[4] E. Ghasemi, M. Ataei, and K. Shahriar, "Prediction of global stability in room and pillar coal mines," Natural Hazards, vol. 72, no. 2, pp. 405-422, 2014.

[5] E. Ghasemi, M. Ataei, and K. Shahriar, "An intelligent approach to predict pillar sizing in designing room and pillar coal mines," International Journal of Rock Mechanics and Mining Sciences, vol. 65, pp. 86-95, 2014.

[6] Y. Yu, K.-Z. Deng, and S.-E. Chen, "Mine size effects on coal pillar stress and their application for partial extraction," Sustainability, vol. 10, no. 3, p. 792, 2018.

[7] N. Zhou, H. Yan, S. Jiang, and Q. Sun, "Stability analysis of surrounding rock in paste backfill recovery of residual room pillars," Sustainability, vol. 11, no. 2, p. 478, 2019.

[8] E. J. Cording, Y. M. A. Hashash, and J. Oh, "Analysis of pillar stability of mined gas storage caverns in shale formations," Engineering Geology, vol. 184, pp. 71-80, 2015.

[9] Y. Zhou, M. Li, X. Xu et al., "Research on catastrophic pillar instability in room and pillar gypsum mining," Sustainability, vol. 10, no. 10, 2018

[10] Y. Zhou, X. Xu, X. Li, M. Li, and Y. Yang, "Study on catastrophe instability of support system in gypsum goaf based on energy dissipation theory," Advances in Civil Engineering, vol. 2018, Article ID 4293584, 9 pages, 2018.

[11] H. Zhang, Z. Wan, Y. Zhang, and D. Wu, "Mechanical properties and failure behavior of composite samples," Advances in Materials Science and Engineering, vol. 2018, Article ID 2545127, 16 pages, 2018.

[12] V. F. Navarro Torres, C. Dinis da Gama, M. Costa e Silva, P. F. Neves, and Q. Xie, "Comparative stability analyses of traditional and selective room-and-pillar mining techniques for sub-horizontal tungsten veins," International Journal of
Minerals, Metallurgy, and Materials, vol. 18, no. 1, pp. 1-8, 2011.

[13] Z. Zhou, Y. Zhao, W. Cao, L. Chen, and J. Zhou, "Dynamic response of pillar workings induced by sudden pillar recovery," Rock Mechanics and Rock Engineering, vol. 51, no. 10, pp. 3075-3090, 2018.

[14] Y. Li, T.-H. Yang, H.-L. Liu, X.-G. Hou, and H. Wang, "Effect of mining rate on the working face with high-intensity mining based on microseismic monitoring: a case study," Journal of Geophysics and Engineering, vol. 14, no. 2, pp. 350-358, 2017.

[15] K. Hashiba and K. Fukui, "Index of loading-rate dependency of rock strength," Rock Mechanics and Rock Engineering, vol. 48, no. 2, pp. 859-865, 2015.

[16] G. Liu, Z. Mu, and J. Du, "Investigation of coal burst characteristics under impact loading," International Journal of Oil Gas and Coal Technology, vol. 18, no. 1-2, pp. 118-145, 2018.

[17] H. B. Li, Q. C. Zhou, Y. Q. Liu, and X. Xia, "Study on the mechanical properties of soft rock under dynamic uniaxial compression," in Advances in Fracture and Failure Prevention, Pts 1 and 2, K. Kishimoto, M. Kikuchi, T. Shoji et al., Eds., pp. 277-281, Springer, Berlin, Germany, 2004.

[18] B. Mahanta, T. N. Singh, P. G. Ranjith, and V. Vishal, "Experimental investigation of the influence of strain rate on strength; failure attributes and mechanism of Jhiri shale," Journal of Natural Gas Science and Engineering, vol. 58, pp. 178-188, 2018.

[19] K. Liu, Q. Zhang, and J. Zhao, "Dynamic increase factors of rock strength," in Proceedings of the 3rd International conference on Rock Dynamics and Applications (RocDyn-3), Trondheim, Norway, June 2018.

[20] F. Gong, L. Zhang, and S. Wang, "Loading rate effect of rock material with the direct tensile and three Brazilian disc tests," Advances in Civil Engineering, vol. 2019, Article ID 6260351, 8 pages, 2019.

[21] H.-Q. Shuang, S.-G. Li, L. Liu, G.-F. Chen, and K.-I. Song, "Use of acoustic emission for the detection of brittle rock failure under various loading rates," Advances in Civil Engineering, vol. 2018, Article ID 5735139, 9 pages, 2018.

[22] M. S. Alam, T. Chakraborty, V. Matsagar, K. S. Rao, P. Sharma, and M. Singh, "Characterization of kota sandstone under different strain rates in uniaxial loading," Geotechnical and Geological Engineering, vol. 33, no. 1, pp. 143-152, 2015.

[23] C. Zou, L. N. Y. Wong, J. J. Loo, and B. S. Gan, "Different mechanical and cracking behaviors of single-flawed brittle gypsum specimens under dynamic and quasi-static loadings," Engineering Geology, vol. 201, pp. 71-84, 2016.

[24] Y. Mahmutoglu, "The effects of strain rate and saturation on a micro-cracked marble," Engineering Geology, vol. 82, no. 3, pp. 137-144, 2006.

[25] L. Changyu, L. Xiao, W. Shengxing et al., "Experimental investigations on rate-dependent stressstrain characteristics and energy mechanism of rock under uniaxial compression," Chinese Journal of Rock Mechanics and Engineering, vol. 31, no. 9, pp. 1830-1838, 2012.

[26] P. L. P. Wasantha, P. G. Ranjith, J. Zhao, S. S. Shao, and G. Permata, "Strain rate effect on the mechanical behaviour of sandstones with different grain sizes," Rock Mechanics and Rock Engineering, vol. 48, no. 5, pp. 1883-1895, 2015.

[27] H. Li, H. Li, B. Gao, D. Jiang, and J. Feng, "Study of acoustic emission and mechanical characteristics of coal samples under different loading rates," Shock and Vibration, vol. 2015, Article ID 458519, 11 pages, 2015.

[28] N. Wang, Y. Xu, D. Zhu, N. Wang, and B. Yu, "Acoustic emission and failure modes for coal-rock structure under 
different loading rates," Advances in Civil Engineering, vol. 2018, Article ID 9391780, 11 pages, 2018.

[29] X. Zhao, J. Liu, W. Zhu et al., Laboratory Testing of AE Precursors of Different Rock Fracture under Uniaxial Compression Condition, China Coal Industry Publishing House, Beijing, China, 2008.

[30] X. Liu, H. Zhang, X. Wang et al., "Acoustic emission characteristics of graded loading intact and holey rock samples during the damage and failure process," Applied SciencesBasel, vol. 9, no. 8, 2019.

[31] P. H. Bischoff and S. H. Perry, "Compressive behaviour of concrete at high strain rates," Materials and Structures, vol. 24, no. 6, pp. 425-450, 1991.

[32] Q. B. Zhang and J. Zhao, "A review of dynamic experimental techniques and mechanical behaviour of rock materials," Rock Mechanics and Rock Engineering, vol. 47, no. 4, pp. 1411-1478, 2014.

[33] H. Xie, J. Zhu, T. Zhou, K. Zhang, and K. Zhou, "Conceptualization and preliminary study of engineering disturbed rock dynamics," Geomechanics and Geophysics for Geo-Energy and Geo-Resources, vol. 6, no. 2, 2020.

[34] A. Jaiswal and B. K. Shrivastva, "Numerical simulation of coal pillar strength," International Journal of Rock Mechanics and Mining Sciences, vol. 46, no. 4, pp. 779-788, 2009.

[35] H. Wang, Y. Jiang, Y. Zhao, J. Zhu, and S. Liu, "Numerical investigation of the dynamic mechanical state of a coal pillar during longwall mining panel extraction," Rock Mechanics and Rock Engineering, vol. 46, no. 5, pp. 1211-1221, 2013.

[36] H. Li, Evaluation Method and Application of Coal Burst Performance under the Effect of Loading Rate, China University of Mining and Technology, Beijing, China, 2014.

[37] C. Fairhurst and J. Hudson, "Draft ISRM suggested method for the complete stress-strain curve for intact rock in uniaxial compression," International Journal of Rock Mechanics and Mining Sciences, vol. 36, no. 3, pp. 279-289, 1999.

[38] K. Mogi, "Study of elastic shocks caused by the fracture of heterogeneous materials and its relation to earthquake phenomena," Bulletin of the Earthquake Research Institute, The University of Tokyo, vol. 40, pp. 125-173, 1962.

[39] X. Peng, X. Cui, C. Li et al., "Design and practice of room \& pillar water-preserved mining for shallowly buried coal seam in north of Shanxi province," Journal of Mining \& Safety Engineering, vol. 25, no. 3, pp. 301-304, 2008, in Chinese.

[40] T. Zhou, J. B. Zhu, Y. Ju, and H. P. Xie, "Volumetric fracturing behavior of $3 \mathrm{D}$ printed artificial rocks containing single and double 3D internal flaws under static uniaxial compression," Engineering Fracture Mechanics, vol. 205, pp. 190-204, 2019.

[41] H. Li, H. Zhou, Y. Jiang, and H. Wang, "An evaluation method for the bursting characteristics of coal under the effect of loading rate," Rock Mechanics and Rock Engineering, vol. 49, no. 8, pp. 3281-3291, 2016. 